NASA/TM-1998-208649

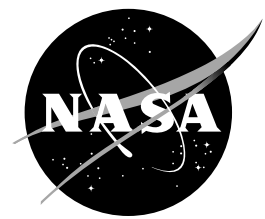

\title{
Challenges to Laser-Based Imaging Techniques in Gas Turbine Combustor Systems for Aerospace Applications
}

Randy J. Locke

Dynacs Engineering Company, Inc., Brook Park, Ohio

Robert C. Anderson, Michelle M. Zaller, and Yolanda R. Hicks

Lewis Research Center, Cleveland, Ohio 
Since its founding, NASA has been dedicated to the advancement of aeronautics and space science. The NASA Scientific and Technical Information (STI) Program Office plays a key part in helping NASA maintain this important role.

The NASA STI Program Office is operated by Langley Research Center, the Lead Center for NASA's scientific and technical information. The NASA STI Program Office provides access to the NASA STI Database, the largest collection of aeronautical and space science STI in the world. The Program Office is also NASA's institutional mechanism for disseminating the results of its research and development activities. These results are published by NASA in the NASA STI Report Series, which includes the following report types:

- TECHNICAL PUBLICATION. Reports of completed research or a major significant phase of research that present the results of NASA programs and include extensive data or theoretical analysis. Includes compilations of significant scientific and technical data and information deemed to be of continuing reference value. NASA's counterpart of peerreviewed formal professional papers but has less stringent limitations on manuscript length and extent of graphic presentations.

- TECHNICAL MEMORANDUM. Scientific and technical findings that are preliminary or of specialized interest, e.g., quick release reports, working papers, and bibliographies that contain minimal annotation. Does not contain extensive analysis.

- CONTRACTOR REPORT. Scientific and technical findings by NASA-sponsored contractors and grantees.
- CONFERENCE PUBLICATION. Collected papers from scientific and technical conferences, symposia, seminars, or other meetings sponsored or cosponsored by NASA.

- SPECIAL PUBLICATION. Scientific, technical, or historical information from NASA programs, projects, and missions, often concerned with subjects having substantial public interest.

- TECHNICAL TRANSLATION. Englishlanguage translations of foreign scientific and technical material pertinent to NASA's mission.

Specialized services that complement the STI Program Office's diverse offerings include creating custom thesauri, building customized data bases, organizing and publishing research results ... even providing videos.

For more information about the NASA STI Program Office, see the following:

- Access the NASA STI Program Home Page at http://www.sti.nasa.gov

- E-mail your question via the Internet to help@sti.nasa.gov

- Fax your question to the NASA Access Help Desk at (301) 621-0134

- Telephone the NASA Access Help Desk at (301) 621-0390

- Write to:

NASA Access Help Desk

NASA Center for AeroSpace Information 7121 Standard Drive

Hanover, MD 21076 
NASA/TM-1998-208649

AIAA-98-2778

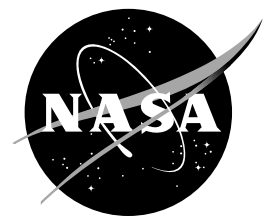

Challenges to Laser-Based Imaging Techniques in Gas Turbine Combustor Systems for Aerospace Applications

Randy J. Locke

Dynacs Engineering Company, Inc., Brook Park, Ohio

Robert C. Anderson, Michelle M. Zaller, and Yolanda R. Hicks

Lewis Research Center, Cleveland, Ohio

Prepared for the

20th Advanced Measurement and Ground Testing Technology Conference sponsored by the American Institute of Aeronautics and Astronautics Albuquerque, New Mexico, June 15-18, 1998

National Aeronautics and

Space Administration

Lewis Research Center 
Available from

NASA Center for Aerospace Information 7121 Standard Drive

Hanover, MD 21076

Price Code: A03
National Technical Information Service 5285 Port Royal Road Springfield, VA 22100 Price Code: A03 


\title{
CHALLENGES TO LASER-BASED IMAGING TECHNIQUES IN GAS TURBINE COMBUSTOR SYSTEMS FOR AEROSPACE APPLICATIONS
}

\author{
Randy J. Locke*, \\ Dynacs Engineering Company, Inc. \\ 2001 Aerospace Parkway, Brook Park, OH 44142 \\ Robert C. Anderson ${ }^{\dagger}$, Michelle M. Zaller ${ }^{\ddagger}$, Yolanda R. Hicks ${ }^{\S}$, \\ NASA Lewis Research Center \\ 21000 Brookpark Rd. Cleveland, OH 44135
}

\begin{abstract}
$\underline{\text { Abstract }}$
Increasingly severe constraints on emissions, noise and fuel efficiency must be met by the next generation of commercial aircraft powerplants. At NASA Lewis Research Center (LeRC) a cooperative research effort with industry is underway to design and test combustors that will meet these requirements. To accomplish these tasks, it is necessary to gain both a detailed understanding of the combustion processes and a precise knowledge of combustor and combustor subcomponent performance at close to actual conditions. To that end, researchers at LeRC are engaged in a comprehensive diagnostic investigation of high pressure reacting flowfields that duplicate conditions expected within the actual engine combustors. Unique, optically accessible flametubes and sector rig combustors, designed especially for these tests, afford the opportunity to probe these flowfields with the most advanced, laser-based optical diagnostic techniques. However, these same techniques, tested and proven on comparatively simple bench-top gaseous flame burners, encounter numerous restrictions and challenges when applied in these facilities. These include high pressures and temperatures, large flow rates, liquid fuels, remote testing, and carbon or other material deposits on combustor windows. Results are shown that document the success and versatility of these nonintrusive optical diagnostics despite the challenges to their implementation in realistic systems.
\end{abstract}

\section{Introduction}

The next generation of aircraft powerplants will operate at conditions resulting in much higher overall

\footnotetext{
* Senior Research Engineer, Aeropropulsion Systems Dept.

† Senior Research Engineer, Optical Instr. Tech. Branch

Research Engineer, Optical Instrumentation Tech., Branch

$\S$ Research Engineer, Combustion Technology Branch

${ }^{1}$ Copyright (C) 1998, The American Institute of Aeronautics and Astronautics Inc. All rights reserved.
}

combustor inlet temperatures and pressures compared with current designs. ${ }^{1}$ A thorough understanding of combustion phenomena and combustor subcomponent performance at actual operating conditions is critical to the successful design and construction of these powerplants. Advances in nonintrusive optical diagnostic methods and test rig designs have now made it possible to acquire twodimensional optical data from within combustors and flame tubes which closely simulate actual engine conditions. Performing experiments of this type, however, requires circumventing or otherwise overcoming inherent problems not typical of benchtop experiments. These problems, both logistical and technical, involve not only the diagnostic techniques, laser beam delivery, and data acquisition, but the test rigs themselves. Frequent combustor configuration changes place an additional burden on the diagnostic techniques requiring a robust design and the ability to adapt to multiple test rigs and frequent component modifications. The techniques must also accommodate other standard, less flexible measurement techniques such as gas sampling by probe extraction. Foremost, these techniques must be able to successfully translate from the bench-top to the powerplant; in other words, they must be capable of remote operation and of performing dependably in a frequently hostile environment.

Many mature optical diagnostic techniques have been used successfully on bench-top or laboratory scale setups and have had a significant impact on combustion studies. ${ }^{2-4}$ Raman techniques, such as coherent anti-Stokes Raman spectroscopy (CARS), have been used for years to study combustion phenomenon and to elucidate information concerning species and temperature. ${ }^{5}$ However, the point-wise and alignment- critical nature of CARS places severe limitations upon its application in an environment where there is a high degree of vibration, large temperature fluctuations, and the test cell is inaccessible during operation. Only recently have advances in the development of spatially resolved Raman spectroscopy been applied to 
combusting flowfields, ${ }^{6}$ although it has yet to be demonstrated in an actual aero-combustor. Similarly, degenerate four-wave mixing ${ }^{7}$ (DFWM) and transient grating spectroscopy ${ }^{8}$ (TGS) have shown great promise as diagnostic tools for high pressure combusting flowfields. However, with problems similar to those experienced by the CARS method, these too have yet to be successfully used in an actual combustor environment.

Laser-induced fluorescence (LIF), planar laserinduced fluorescence (PLIF), and recently, analog predissociative techniques have been used successfully to examine a wide range of combustion processes. The two-dimensional nature of PLIF has made it the more promising and useful of the two for aerospace gas turbine combustor applications. Additionally, its multi-species selectivity, flow field imaging capabilities, and potential quantitative nature make it a favorable candidate for flame studies.

PLIF has been used previously to probe laboratory scale low pressure and atmospheric pressure gaseous flames for species concentration and distribution,, , 10 velocity $^{11}$, and temperature ${ }^{12}$ measurement. Shock tube studies by PLIF methods ${ }^{13}$ have also enjoyed significant success including temperature and species measurement. Recently, laboratory scale high pressure gaseous flames near 1.0 - 4.0 MPa, ${ }^{14,15}$ and spray flames approaching $1.0 \mathrm{MPa}^{16}$ have been successfully examined via PLIF imaging. PLIF Measurements made using optically accessible ground based power systems ${ }^{17}$, diesel ${ }^{18}$ and spark ignition $^{19}$ (SI) engines have been critical to understanding the combustion processes in these systems. Recent two-dimensional fluorescence imaging measurements which simulate proposed gas turbine concepts but at atmospheric pressures have also been successfully performed ${ }^{20}$.

While these investigations have produced significant results and have added greatly to our understanding of combustion processes, these experiments have only simulated certain aspects of the combustor and its operating conditions. What was needed was a means to nonintrusively examine the combusting flowfield, and to observe the performance of combustor subcomponents, such as the fuel injector and swirlers, operating at anticipated conditions of pressure and temperature, using jet fuels. The test rigs necessary to allow this type of testing present many challenges to successful application of optical diagnostics. Conditions approaching 6.1 - 10.1 MPa in pressure, $2255 \mathrm{~K}$ in temperature, and mass flows approaching $17 \mathrm{~kg} / \mathrm{s}$ are under consideration for future tests. Furthermore, the very nature of this type of testing requires remote operation of all aspects of the diagnostics procedures. This includes laser operation, data/image acquisition, and test rig operation. Optical accessibility to the combustion and fuel injection zones is also required, necessitating the application of complex window cooling technologies to prevent degradation and potential melting of window materials.

At NASA LeRC, efforts have been underway to adapt and implement existing nonintrusive optical diagnostics methods to examine the realistic, reacting flow fields generated by advanced fuel injector designs. Two optically accessible flametubes capable of operation up to $2.0 \mathrm{MPa}$ in pressure and $2033 \mathrm{~K}$ in temperature with flow rates up to $3.68 \mathrm{~kg} / \mathrm{s}$ are presently in use. A third, much larger housing designed for $6.7 \mathrm{MPa}$ operation, has been delivered and installed but has not yet undergone optical testing. For these tests, optical accessibility is the key. Window materials must be fully capable of withstanding the above conditions while remaining optically clear for the acquisition of meaningful data and images.

Due to testing costs and strict scheduling constraints which precluded more time consuming individual testing, each diagnostic had to be integrated with the test rig in such a way as to allow simultaneous data acquisition. The optically accessible rigs at LeRC were designed to allow implementation of a large number of optical diagnostic methods. PLIF and Planar Mie scattering were chosen as the primary methods since adequate laser energy exists to make an acceptable laser sheet and the same UV excitation wavelength can be used for both. Furthermore, these techniques, in addition to having high temporal and spatial resolution and high sensitivity, allow an opportunity to examine both intermediate and stable species.

\section{Hardware}

The test facility at NASA LeRC delivers nonvitiated air to the two unique, optically accessible combustor test rigs utilized for this series of experiments and described in detail elsewhere. ${ }^{21-22}$ The first, pictured in Figure 1a, is a $21.6 \mathrm{~cm}$ x $21.6 \mathrm{~cm}$ radially-staged gas turbine combustor. This rig, called a sector rig, is designed to test larger, multi-component injector systems. The second test rig, shown in Figure $1 \mathrm{~b}$, measuring $7.6 \mathrm{~cm} \times 7.6 \mathrm{~cm}$, is a flame tube designed to test single component injectors or small, multi-component systems. Typical rig operating conditions range from inlet temperatures of $533 \mathrm{~K}$ $866 \mathrm{~K}$, inlet pressures of $0.55 \mathrm{MPa}-2.03 \mathrm{MPa}$, and mass flows of $0.16 \mathrm{~kg} / \mathrm{s}$ to $0.77 \mathrm{~kg} / \mathrm{s}$ for the flame tube, and $1.13 \mathrm{~kg} / \mathrm{s}-3.63 \mathrm{~kg} / \mathrm{s}$ for the sector rig. Equivalence ratios $(\phi)$ range from 


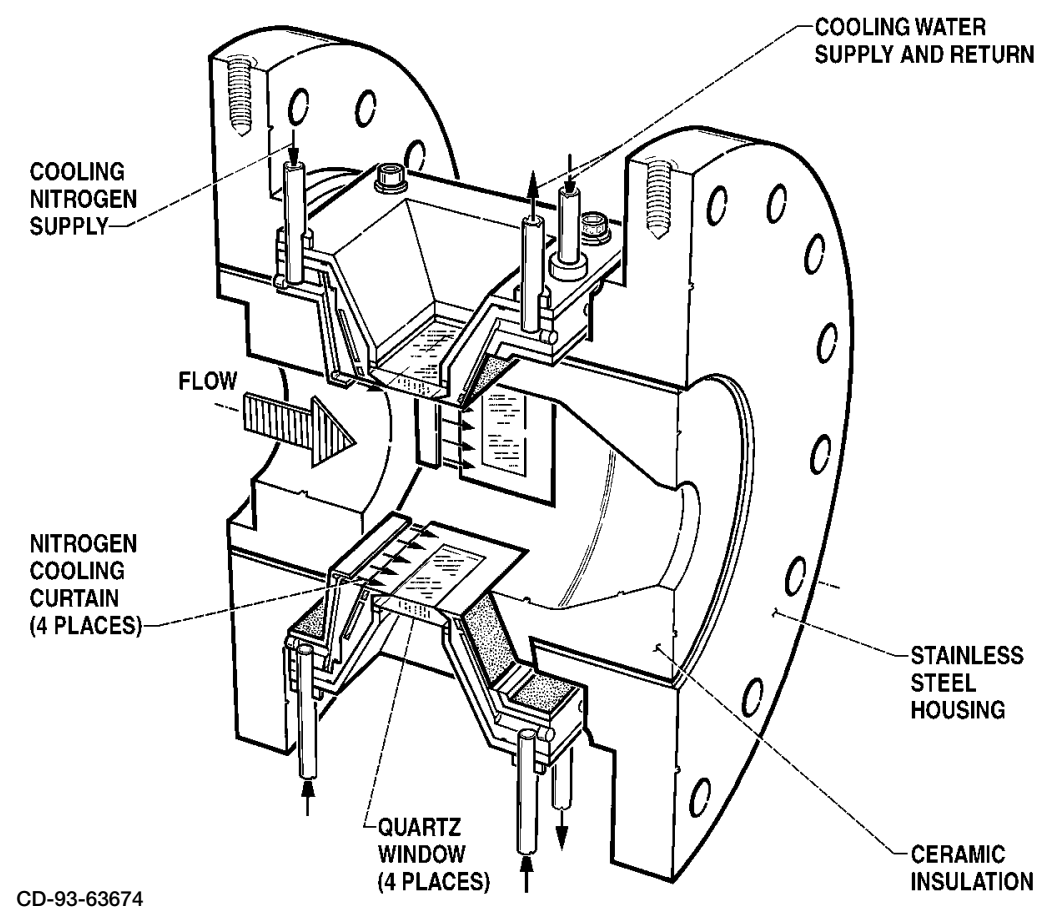

Figure 1a. Optically accessible radially-staged gas turbine sector housing.

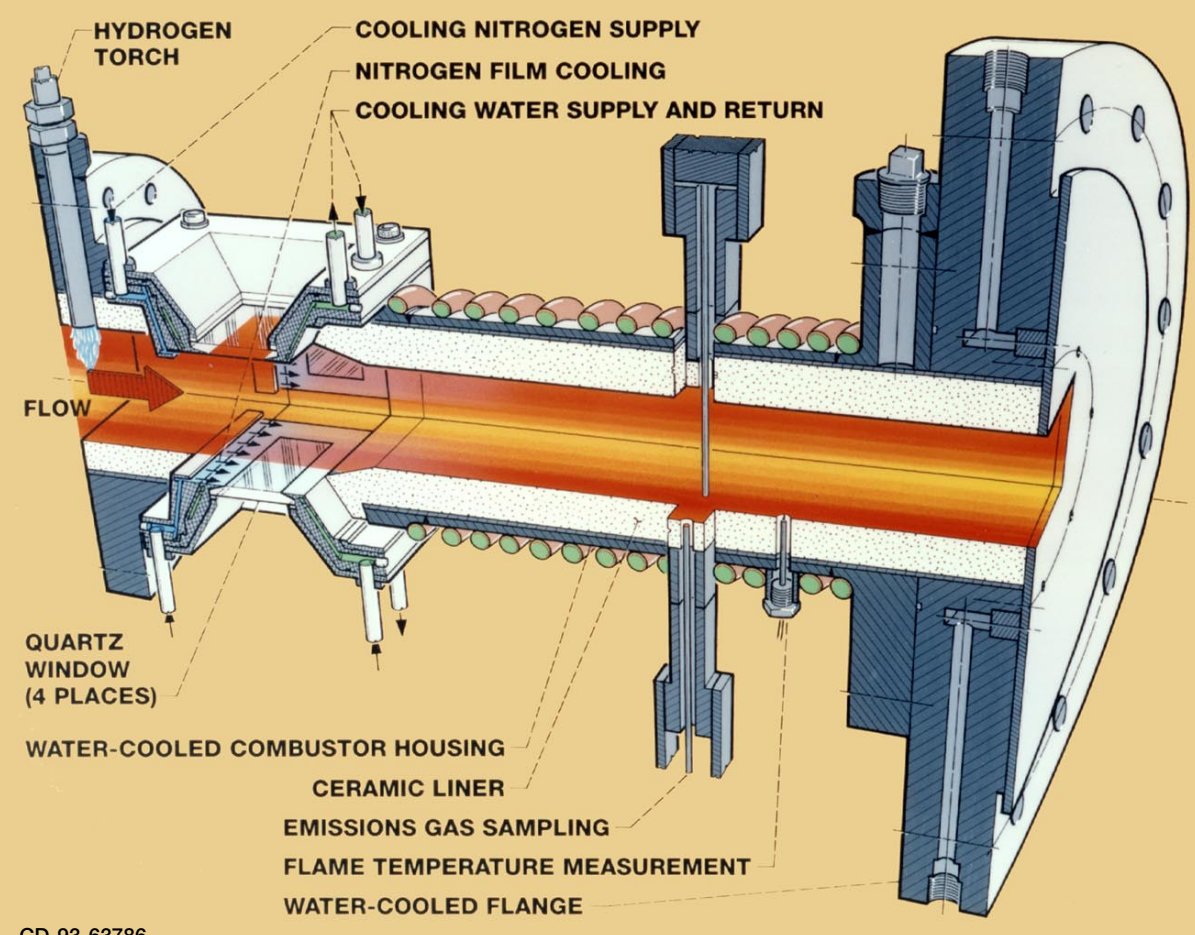

Figure 1b. Optically accessible flametube housing. 
0.30 to 0.60 . Initially JP-5 or JP-8 jet fuel was used for testing but Jet-A is now used for all tests.

The window housings, which are identical for each test rig, are equipped with UV grade fused silica windows measuring $38 \mathrm{~mm}$ axially, $51 \mathrm{~mm}$ radially, and $13 \mathrm{~mm}$ thick. To counter the heat generated in the combusting flow stream, the inner surface of the windows are cooled with a thin film of nitrogen. The nitrogen flow comprises less than $10 \%$ of the aggregate combustor mass flow and maintains a typical window inner surface temperature less than $977 \mathrm{~K}$.

Window breakage has not been a major problem. Breakage, which typically occurs in the form of shear cracks, has been experienced only on the larger sector rig. Cracks have not occurred during a test run but only after the shutdown procedure has been completed and the rig is cooling down. Since breakage does not happen often and not always at the same location, it cannot be directly attributed to any one cause. However, it is assumed that the breakage occurs as a result of uneven cooling of the window mounts and the combustor thereby causing uneven stresses.

Window deposits are a recurring problem at certain test conditions. While testing specific fuel injector designs, it became necessary to periodically remove deposits that accumulated on the windows. This is accomplished by first retracting the ICCD cameras out of the way, then remotely sweeping a $50 \mathrm{~mJ}$ sheet of focused, $532 \mathrm{~nm}$ output provided by a Continuum "Surelite" Nd:YAG laser over both detector windows. In this manner, the deposits are ablated from the interior window surfaces. Cleaning the laser beam insertion window was found to be unnecessary since the continued panning of the incident $281 \mathrm{~nm}$ laser sheet effectively keeps this window clear.

A direct result of test rig heating is axial growth. Each rig demonstrates this characteristic to a varying degree. This growth is always in the upstream direction since the downstream segment of the rig is anchored to the test bed. Growth of up to $7-8 \mathrm{~mm}$ has been observed. Tracking and correcting for this growth with the incident lasers and cameras under remote control was an additional challenge during these experiments. This is achieved by scribing the combustor housing just below one of the imaging windows in millimeter increments. The output beam from a helium neon laser was then spotted at the origin of this ruling and monitored with a video camera throughout the test run. As the rig grows or shrinks with changing conditions, this beam spot is observed to drift along the scaled ruling. The camera and laser sheet delivery system are then shifted an equal amount in the same direction, thereby maintaining the original, pre-lightoff alignment.

Various fuel injector designs have been fitted into each test rig. These injectors are positioned such that the injector exit plane projects approximately 5 $\mathrm{mm}$ into window viewing area, thereby providing a reference point for the resultant images and rig coordinate system. The rig coordinate system defines $\mathrm{x}$ as the azimuthal or horizontal direction with positive $\mathrm{x}$ to the right when looking upstream. $\mathrm{Z}$ is the axial coordinate, with $\mathrm{z}=0$ defined as the injector exit plane and positive $\mathrm{z}$ in the downstream direction. $\mathrm{Y}$ is the radial or vertical coordinate with positive values above the rig center line.

\section{Optical Setup}

Figure 2 presents a cutaway of the test facility and the experimental layout which is described in detail elsewhere. $^{23}$ The $10 \mathrm{~Hz}, 532 \mathrm{~nm}$ output from a Continuum model ND-81C, Nd:YAG laser pumps a ND 60 dye laser, the output of which is doubled by a UVX ultra-violet wavelength extension system. The resulting $281 \mathrm{~nm}$ output, maintained at approximately $20 \mathrm{~mJ}$ for the experiments described herein, is delivered through $90 \mathrm{~mm}$ acrylic tubes to the test cell by a series of remotely controlled high damage threshold mirrors. Since this laser provided a divergence of only 5 mrads, the laser output is allowed to freely expand over the beam path which ranges from 12 meters for the flame tube to 25 meters to the sector rig. The laser beam, prior to entering the test section, is formed into a sheet by a $\mathrm{f}=3000 \mathrm{~mm}$ cylindrical lens. The resultant sheet size at the laser focal volume is approximately $22 \mathrm{~mm}$ by $0.3 \mathrm{~mm}$. A second beam path, not shown in the figure, has recently been added to allow simultaneous two color experiments or the use of a second YAG laser for window cleaning operations.

Due to the distances involved, and to safety considerations demanding that the test cell be inaccessible to personnel during all test runs, positioning of the laser sheet and cameras by remote computer control is necessary. For the nearer flame tube rig, this requires controlling, effected by a Parker Hannifin Compumotor model 3000, up to four axes on the laser sheet positioning table suspended immediately above the windowed test section (see figure 2). Control of two Aerotech 3-axes positioners, each holding an ICCD camera, is accomplished via two Unidex model 11 controllers. For the more distant sector rig, a Compumotor model 4000 provides control for an additional 4 axes which are required for laser sheet delivery into that test section. 


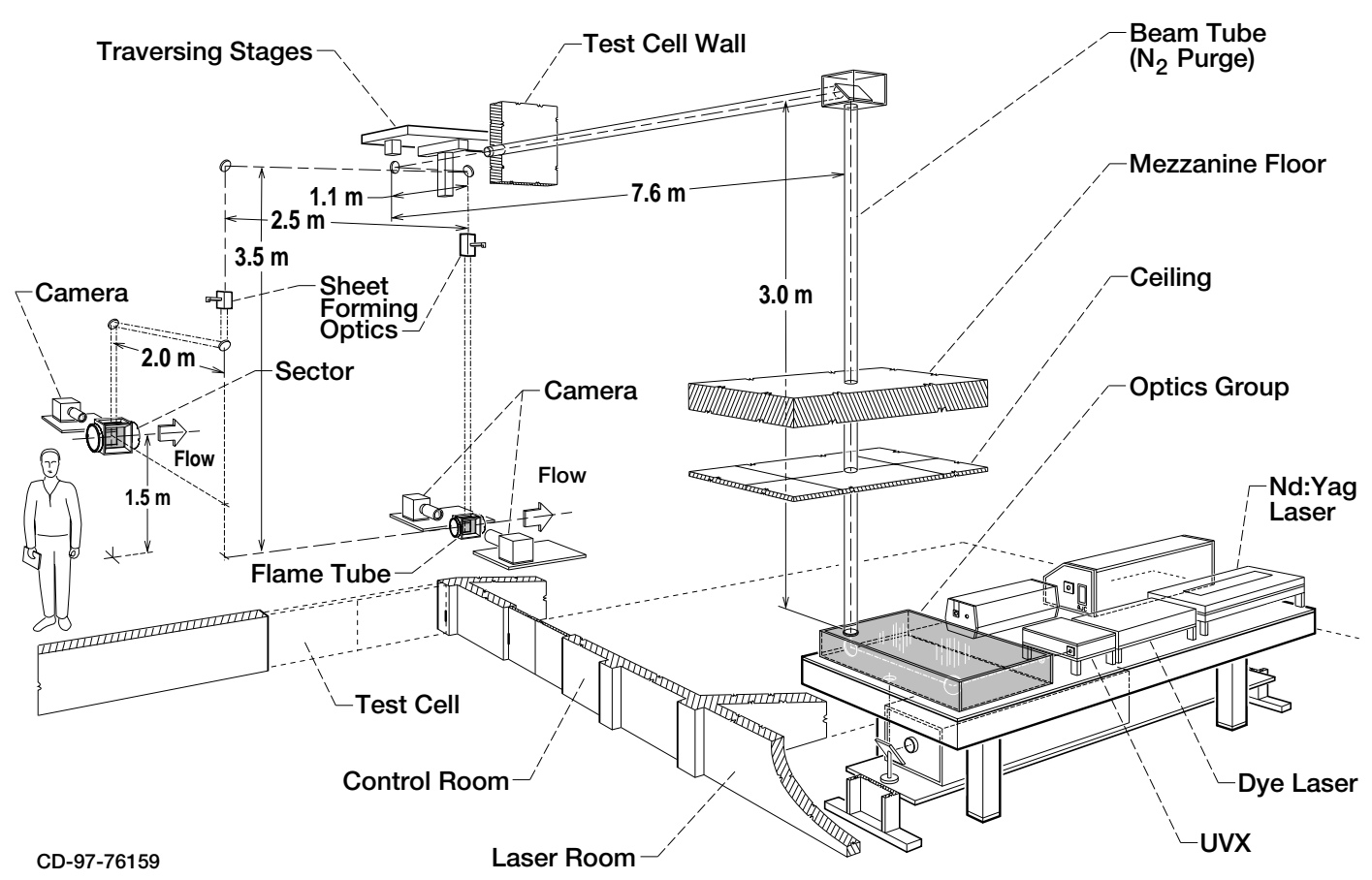

Figure 2. Optically diagnostic gas turbine test rig facility.

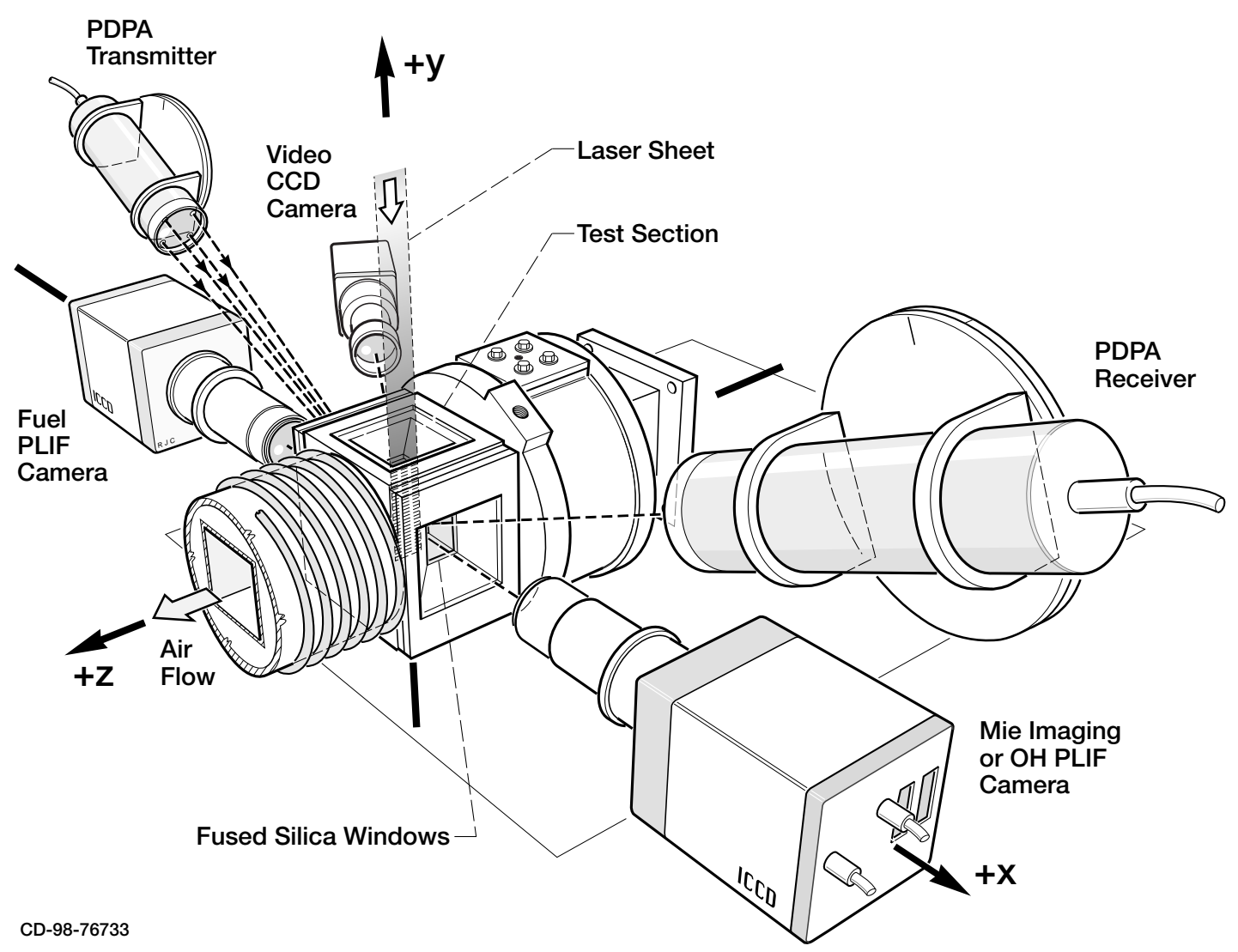

Figure 3. Optical diagnostic experimental configuration. 
The complexity of this motion control system was reduced by writing a computer program to coordinate the simultaneous positioning of both the laser sheet and camera detection systems. The LabWindows/CVI software development tool from National Instruments was used to accomplish this task. The final program allows the user to select which laser beam and detector configuration is to be utilized for each test run from a possible ten combinations. The program also provides a high degree of flexibility by allowing the user to specify the type and orientation of each stage mounted in the test cell and how these stages are to be connected to the motion controllers. The program controls the distance and direction that each designated stage moves and allows the user to define an origin. The program, through keyboard command, positions the laser sheet anywhere within the insertion window with respect to the defined origin in terms of a rectangular coordinate system. The program records the user's coordinates, test conditions, as well as origin for future test runs or in case of a power failure.

Figure 3 illustrates the typical diagnostic setup used for this series of experiments. Fuel or OH PLIF and planar Mie scattering signals are collected normal to the incident laser sheet by gated and intensified 16 bit ICCD cameras from Princeton Instruments, each with a 384 x 576 pixel array. The intensifiers, adjusted to provide a $75 \mathrm{~ns}$ gate, are synchronously triggered with the laser pulse. Each camera uses a Nikon $105 \mathrm{~mm}$ f/4.5 UV Nikor lens focused on a plane coincident with the incident laser sheet. The PLIF camera is equipped with both a Schott WG-305 filter and a narrow band interference filter centered at $315 \mathrm{~nm}$ with a FWHM of $10.6 \mathrm{~nm}$ yielding a transmission efficiency of $16 \%$. The Mie scattering camera is equipped with a narrow band interference filter centered at $283 \mathrm{~nm}$ with a FWHM of $2 \mathrm{~nm}$ and a transmission efficiency of $6 \%$. Both single shots and on chip-averaging of successive images may be obtained using this detection system.

Figure 3 also shows the placement of a twocomponent Aerometrics Phase/Doppler particle analyzer (PDPA). This instrument is used to measure the light refractively scattered by fuel droplets $\left(30^{\circ}\right.$ forward scatter). The PDPA system is mounted onto a large 3-axis Accudex positioner from Aerotech. The two-line $488 \mathrm{~nm}$ and $514 \mathrm{~nm}$ output is supplied by an argon ion laser from Coherent and delivered by fiber optic to the transmitter unit. The transmitter and receiver are aligned $15^{\circ}$ from the horizontal plane to maximize the number of measurement sites within the test section. The focal lengths for both receiving and transmitting optics are $500 \mathrm{~mm}$. The transmitter beam separations are 40 $\mathrm{mm}$. Droplet size, velocity and number density distributions may be obtained by shifting the data acquisition site along the propagation direction of the transmitter. Since the PDPA device makes point measurements within a small region, the probe volume must be traversed under remote control throughout the accessible flowfield to characterize the spray.

Originally each of these diagnostics were aligned separately, which led to difficulties in spatially correlating the data acquired from each method. Subsequently a single, universal alignment tool is used for each method. This constitutes a flat plate measuring $19 \mathrm{~mm}$ x $96 \mathrm{~mm}$ which is scribed on both sides with a metric ruling, and arrows indicating both the flow direction and the laser sheet path. The plate is inserted through the lower window location which was fitted with a spark plug for these experiments, and extends through the flow path a measured distance from the fuel injector exit plane. For reference, the center line of the combustor is also scribed into the plate. Holes measuring $3 \mathrm{~mm}$ in diameter are located along this center line for the purposes of aligning the PDPA instrument. Following alignment, the plate is withdrawn and the spark plug replaced.

\section{Image Acquisition and Processing}

Image collection is accomplished using Princeton Instrument's Winview software. The collected images are transferred to an SGI Indigo workstation for processing. Processing and image analysis on the SGI is accomplished using PV-WAVE from Visual Numerics, Inc. The gray scale images from the cameras are converted for display using a pseudocolor scale consisting of 25 color plus black (low intensity) and white (high intensity) where each color represents a span of 10 counts in a linear span of 255. The colors in the pseudocolor scale have been chosen to make it easier to see details in the less intense portions of the images. Image processing includes removal of noise spikes, background subtraction, and, in some cases, correction for laser sheet energy distribution.

We have also developed an additional, unique image processing capability that allows us to obtain views looking upstream into the fuel injectors. These views, called end-on or "cross flow" views, were developed to examine the fuel spray pattern or patternation of each fuel injector studied. In this process, forty-one side-view images are acquired at 1 $\mathrm{mm}$ increments across the flow field at each test condition. A computer program then configures these 41 images into an image stack. The program interpolates the region between each of the 41 individual images thereby filling in the gaps resulting in a smoothed 3-D image block. The image block 
can then be sliced in any desired orientation. Figure 4 illustrates this process for a lean direct injector design installed in the sector rig. In this figure the flow exits the page to the right. The left side of the image shows, for the sake of simplicity, only a few selected side-view fuel fluorescence images in the $\mathrm{z}$ $y$ plane. The right side of the figure shows a few of the resultant cross flow views obtained in the manner described. The images in an image stack are scaled together so that the highest signal level represents the 99th percentile. The images are displayed in this manner in order to accentuate the lower light level structures that would otherwise be lost in the glare of the higher intensity features.
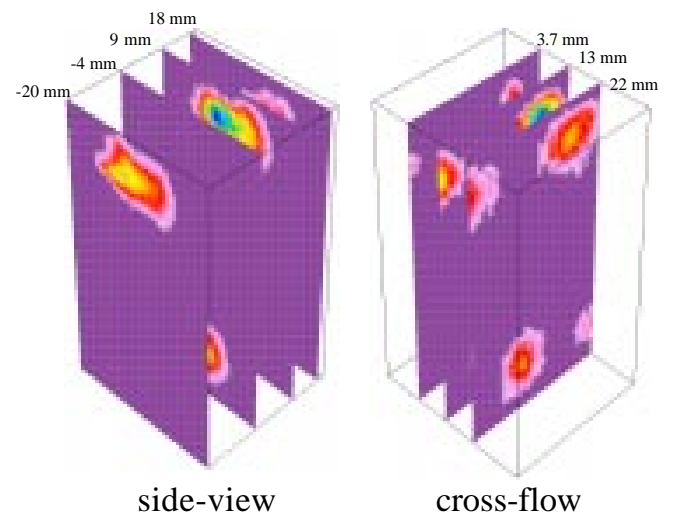

Figure 4. Sequential image stacking of side-view (z-y plane) fuel PLIF images acquired within the sector combustor yielding cross-flow (x-y) views. Test conditions: $\lambda_{\text {exc }}=281.5 \mathrm{~nm}, \mathrm{~T}_{\text {inlet }}=800 \mathrm{~K}, \mathrm{P}_{\text {inlet }}=1.46$ $\mathrm{MPa}, \phi_{\text {total }}=0.42$

Because the injectors are positioned with their injector exit planes projecting approximately $5 \mathrm{~mm}$ into the window viewing area, a large amount of incident laser light scatter from the injector face is encountered. This scatter is intense enough to allow passage of a small but significant portion through the selective filters of the detectors. This scatter is eliminated by placing an external beam block over the top of the laser sheet insertion window effectively blocking any light from hitting the face of the fuel injector.

Since direct measurement of the laser sheet intensity in the $\mathrm{z}$ direction is not practical, another technique has been developed to correct for the fall off in laser sheet power at the upstream and downstream edges. We assume that the average intensity in the crossflow images over an area enclosing the jet should be constant as we move downstream over the relatively short axial range we can see. This is a reasonable assumption because the viewable distance is relatively short (approximately $40 \mathrm{~mm}$ ). This assumption leads to the conclusion that any variation in this average is due to laser sheet energy changes. In our recent work, we have chosen to correct the xyimages by a factor which causes the within-jet average to be a constant over a range of $\mathrm{z}$ values.

The left-hand image in figure 5 shows a typical side view, fuel fluorescence image obtained on the flame tube rig for a two-circuit fuel injector concept. The test conditions were: $P_{\text {inlet }}=1.6 \mathrm{MPa}, T_{\text {inlet }}=680 \mathrm{~K}$, $\phi_{\text {total }}=0.31$, and $\lambda_{\text {exc }}=281.5 \mathrm{~nm}$. This image illustrates one of the challenges encountered in these experiments and brings out one of the many benefits. The problem illustrated here is the obscuration of the fluorescence signal by the buildup of soot on the detector windows. This deposition is seen here as a dark mass in the upstream (left) center position, just downstream of the injector location. The benefit illustrated is the ability to illuminate the detailed flowfield structure. This image, taken at the center line of the injector clearly shows the spray from both inner and outer fuel circuits. This imaging data has been used to calculate the full fuel spray angle at condition and subsequently found to agree quite well with the theoretical values at most test points. The soot buildup at low power condition, while problematic, was easily removed by the ablation method described earlier.

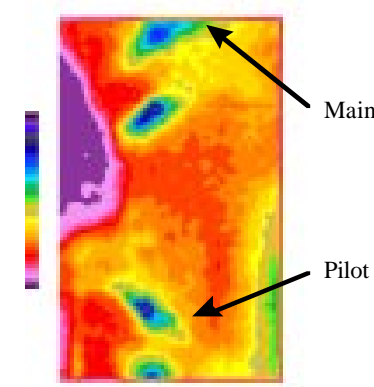

Side View

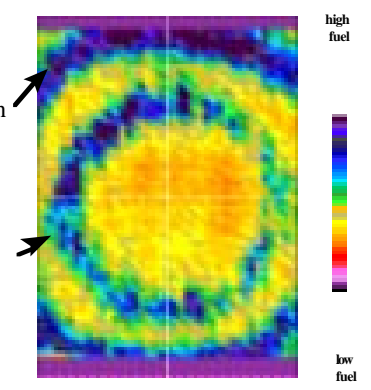

Cross Flow
Figure 5. Comparison of side-view and cross-flow views acquired for a two-circuit injector installed in the flametube. Test conditions: $\lambda_{\text {exc }}=281.5 \mathrm{~nm}, \mathrm{~T}_{\text {inlet }}=$ $682 \mathrm{~K}, \mathrm{P}_{\text {inlet }}=1.6 \mathrm{MPa}, \phi_{\text {total }}=0.304$

The right-hand image in figure 5 presents a cross flow image derived using the above described technique for a position $14 \mathrm{~mm}$ downstream from the fuel injector exit plane. The advantages of the cross flow display are quite obvious. Actual flow structure and fuel spray symmetry are clearly illuminated. In the fuel PLIF image, two concentric rings of fuel, either vapor and/or liquid, are seen to be coming out of the page and expanding away from the two-circuit injector with a high degree of uniformity.

Figure 6 shows the fuel PLIF cross flow image shown in figure 5 (right) compared with a planar Mie scattering cross flow image acquired simultaneously 
at the same axial position. The fuel PLIF image again shows two concentric rings of fuel from the pair of injectors. In contrast, the planar Mie image shows only a single ring emanating from the inner fuel circuit, the outer ring is absent. The reason for this is due to the outer fuel circuit's apparent greater efficiency at vaporizing the fuel spray, which explains the lack of droplet scattering centers in this region. This comparison offers a means by which to address critical fuel vaporization issues which have been examined by other methods ${ }^{24,25}$ but with limited success.



Another issue brought forward by considering figure 6 is the question of possible extinction effects. The right side in the PLIF image and the left side of the planar Mie scattering image, each being the side opposite their respective cameras, appear to show some decrease in signal intensity. This affect may be attributed to the extinction of the incident light sheet or to the extinction of the induced emission or scattering by the intervening flowfield. Since this phenomenon is not ubiquitous, but only appears thus far in test runs involving high pressures and large mass flows, we have as yet not investigated the extinction question thoroughly. Obviously, with tests scheduled to begin using the high pressure $6.08 \mathrm{MPa}$ rig where extinction effects may be more severe, the investigation of these effects should be accomplished.

Tests were performed in which PLIF, Planar Mie scattering, and PDPA were each attempted. These tests were originally performed simultaneously with good results. However, due to the close tolerances in positioning the three different diagnostics (see figure 3 ), a few instances of unwelcome collisions between the various optical components occurred. In these collisions, optical alignment was invariably lost for one or more of the detectors requiring shutdown of the rig in order to re-enter the test cell to realign the systems. Subsequently, the PDPA diagnostics were run only after moving the two ICCD cameras a safe distance downstream following their data acquisition run.

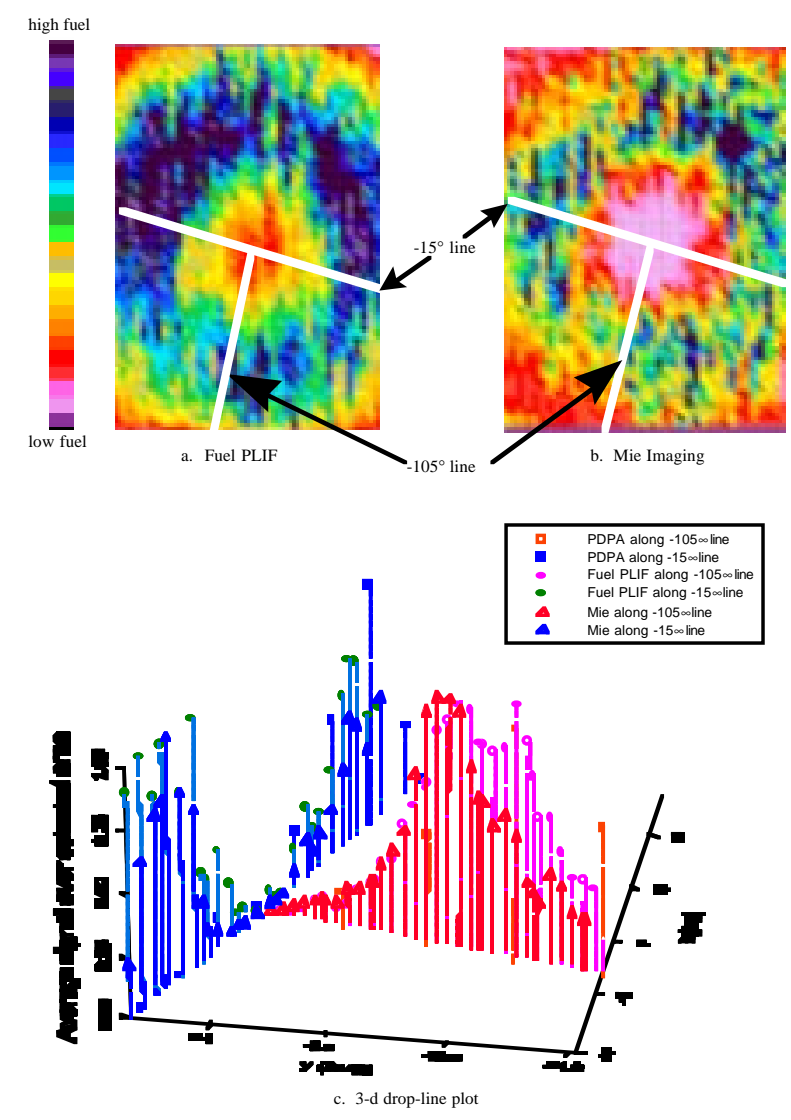

Figure 7. Comparison of fuel volume distribution as measured by PLIF, Mie Scattering and PDPA acquired at the same axial location. Lines in the images indicate the path along which PDPA measurements were made. Conditions: $\lambda_{\mathrm{exc}}=281.5 \mathrm{~nm}, \mathrm{~T}_{\text {inlet }}=616$ $\mathrm{K}, \mathrm{P}_{\text {inlet }}=558 \mathrm{kPa}, \phi_{\text {total }}=0.445$

Figure 7 shows a comparison of the data acquired at the same axial location, $12.7 \mathrm{~mm}$ from the fuel injector exit plane, for each of the three techniques; PDPA, PLIF and planar Mie. For this series of experiments the flametube was equipped with a twocircuit fuel injector with only the pilot operating under the following flow conditions: $T_{\text {inlet }}=616 \mathrm{~K}$, $\mathrm{P}_{\text {inlet }}=558 \mathrm{kPa}, \phi=0.445, \lambda_{\text {exc }}=281.5 \mathrm{~nm}$. The white lines labeled $-105^{\circ}$ and $-15^{\circ}$ on the PLIF and Mie images denote the path along which PDPA mass flux data was acquired. The graph at the bottom of the figure plots both the pixel intensity along the $-105^{\circ}$ (open symbols) and $-15^{\circ}$ (solid symbols) lines from the PLIF and Mie images and the mass flux data 
acquired from PDPA measurements. From the plot, close agreement between the three different techniques is seen to exist along the $-105^{\circ}$ line. Along the $-15^{\circ}$ line, the agreement holds only for the data along the positive $\mathrm{x}$ axis. Along the minus $\mathrm{x}$ axis, the PDPA data falls off sharply. There are two possible causes for this observation; first may be the obscuration of the PDPA receiver due to the severe beam insertion angle involved. The second potential cause may be that of extinction of the scattered light from the far side of the flametube by the intervening flow. This data falloff has been observed prior to this on high pressure vaporizing sprays ${ }^{26}$. The approximate 1-2 $\mathrm{mm}$ shift between the maxima for the three techniques on each of the plotted $-105^{\circ}$ and $-15^{\circ}$ lines is a vestige of using separate alignment methods. This has subsequently been eliminated by using the same alignment tool previously described for each of the diagnostics.

\section{$\underline{\text { Conclusions and Future Considerations }}$}

We have demonstrated at NASA Lewis that various relatively mature laser diagnostic techniques can successfully be applied simultaneously to the realistic flowfields of high pressure and temperature aero-combustor test rigs. Images have been obtained through PLIF and planar Mie scattering measurements providing heretofore never before seen views of the combustion process and fuel injector operation at actual conditions. Our methods are evolving with experience and changes are continuously being made to improve or adapt diagnostic techniques to these large scale rigs. For example a remotely controlled motorized filter wheel is planned to be used on the ICCD cameras for all future imaging. The filter wheel, which holds up to five, two-inch diameter filters, will effectively increase our diagnostic capabilities by increasing the number of species and other flow parameters that can be examined in a single test run. Additionally, it will allow exact comparison between PLIF and Planar Mie scattering results thereby eliminating the need for corrections such as magnification, and pixel response variations, required when two different cameras are used.

Another example of continuous improvement is the advent of a new $1.0 \mathrm{~nm}$ FWHM narrowband interference filter making it possible to record $\mathrm{OH}$ PLIF by eliminating a majority of the interference of fluorescence signals in the region of the fuel injector exit plane. Until recently fuel fluorescence was examined rather than $\mathrm{OH}$ fluorescence because this interference precluded good OH PLIF measurements.

Further planned improvements include automating the process by which cross flow views are generated.
This will speed up one of the most time consuming aspects of the analysis. Additionally, topographical and three-dimensional plotting of image pixel intensity, which provides an easier means to examine the flow path, are also being automated.

The means to make corrections for laser sheet inhomogenieties such as those recently reported ${ }^{27}$ are also being investigated. However, difficulties due to mandatory remote operation, and the fact that both the laser sheet and the resultant planar fluorescence and scattering must both pass through different windows of questionable transparency makes this a daunting task.

\section{$\underline{\text { References }}$}

1. V. J. Lyons and R. W. Niedzwiecki, "Combustor Technology for Future Small Gas Turbine Aircraft," NASA Technical Memorandum, TM1063112, (1993).

2. K. Kohse-Höinghaus, "Laser Techniques for the Quantitative Detection of Reactive Intermediates in Combustion Systems," Prog, Energy Combust. Sci., 20, 203, (1994).

3. E. W. Rothe and P. Andresen, "Application of Tunable Excimer Lasers to Combustion Diagnostics: A Review," App. Optics, 36, No. 18, 3971, (1997).

4. A.M.K.P. Taylor, ed., Instrumentation For Flows With Combustion, Academic Press, (1993).

5. A. C. Eckbreth, Laser Diagnostics for Combustion Temperature and Species, Abacus Press, (1988).

6. G. Grunefeld, V. Beushausen, P. Andresen, and W. Hentschel, "Spatially Resolved Raman Scattering for Multi-Species and Temperature Analysis in Technically Applied Combustion Systems: Spray Flame and Four-Cylinder InLine Engine," Appl. Phys. B, 58, 333, (1994).

7. M. S. Brown, L. Rahn, and T. Dreier, "HighResolution Degenerate Four-Wave Mixing Spectral Profiles of OH," Opt. Lett., 17, No. 1, 76, (1992).

8. M. S. Brown and W. L. Roberts, "Diagnostics in Reacting Flows Using Transient Grating Spectroscopy," AIAA 98-0235, AIAA 36th Aerospace Sciences Meeting, Reno, (1998).

9. B. A. Williams and J. W. Fleming, "Comparative Species Concentrations in $\mathrm{CH}_{4} / \mathrm{O}_{2} / \mathrm{Ar}$ Flames Doped With $\mathrm{N}_{2} \mathrm{O}$, NO and $\mathrm{NO}_{2}$," Comb. and Flame, 98, 93, (1994). 
10. M. Versluis, N. Georgiev, L. Marttinsson, M. Aldén, and S. Kröll, "2-D Absolute $\mathrm{OH}$ Concentration Profiles in Atmospheric Flames Using Planar LIF in a Bi-Directional Laser Beam Configuration," Appl. Phy. B, 65, 411, (1997).

11 P. Barker, A. Thomas, T. McIntyre, and $\mathrm{H}$. Rubinsztein-Dunlop, "LEI Velocimetry and PLIF Thermometry of Supersonic Flow Around a Cylindrical Body," AIAA 97-0496, 35th AIAA Aerospace Sciences Meeting and Exhibit, Reno, 1997.

12. J. M. Seitzman, G. Kychakoff, and R. K. Hanson, "Instantaneous Temperature Field Measurements Using Planar laser-Induced Fluorescence," Opt. Lett., 10, No. 9, 439, (1985).

13. J. M. Seitzman, J. L. Palmer, A. L. Antonio, R. K. Hanson, P. A. DeBarber, and C. F. Hess, "Instantaneous Planar Thermometry of ShockHeated Flows Using PLIF of OH," AIAA 930802, AIAA 31st Aerospace Sciences Meeting and Exhibit, Reno, (1993).

14. C. Schilz, V. Sick, J. Heinze, and W. Stricker, "Laser-Induced Fluorescence Detection of Nitric Oxide in High Pressure Flames With A - X $(0,2)$ Excitation," App. Opt., 36, No. 15, 3227, (1997).

15. B. E. Battles, J. M. Seitzman, and R. K. Hanson, "Quantitative Planar Laser-Induced Fluorescence Imaging of Radical Species in High Pressure Flames," AIAA 94-0229, AIAA 32nd Aerospace Science Meeting and Exhibit, Reno, (1994).

16. M. G. Allen, K. R. McManus, and D. M. Sonnenfroh, "PLIF Imaging in Spray Flame Combustors at Elevated Pressure," AIAA 950172, AIAA 33rd Aerospace Sciences Meeting and Exhibit, Reno, (1995).

17. M. Versluis, M. Boogaarts, R. Klein-Douwel, B. Thus, W. De Jongh, A. Braam, J. J. Ter Meulen, W. L. Meerts, and G. Meijer, "Laser-Induced Fluorescence Imaging in a $100 \mathrm{~kW}$ Natural Gas Flame," Appl. Phys., B, 55, 164, (1992).

18. A. Arnold, F, Dinkelacker, T, Heitzmann, P. Monkhouse, M. Schafer, V. Sick, J. Wolfrum, W. Hentschel, and K. -P. Schindler, "DI Diesel Engine combustion visualized by Combined Laser Techniques," Twenty-Fourth Symposium (International) on Combustion, Combustion Institute, 1605, (1992).
19. M. Knapp, A. Luczak, H. Schlüter, V. Beushausen, W. Hentschel, and P. Andresen, "Crank-Angle Resolved Laser-Induced Fluorescence Imaging of NO in a Spark-Ignition Engine at $248 \mathrm{~nm}$ and Correlations to Flame Front Propagation and Pressure Release," App. Opt., 35, No. 21, 4009, (1996).

20. W. Shih, J. G. Lee and D. A. Santavicca, Stability and Emissions Characteristics of a Lean Premixed Gas Turbine Combustor," Twenty-Sixth Symposium (International) on Combustion, Combustion Inst., Pittsburgh, 2771, (1996).

21. R. J. Locke, Y. R. Hicks, R. C. Anderson, K. A. Ockunzzi, and H. J. Schock, "Imaging of Combustion Species in a Radially-Staged Gas Turbine Combustor," NASA TM 107373, (1996).

22. R. J. Locke, Y. R. Hicks, R. C. Anderson, and K. A. Ockunzzi, "OH Imaging in a Lean Burning High-Pressure Combustor," AIAA Journal, 34, No. 3, 622, (1996).

23. R. J. Locke, Y. R. Hicks, R. C. Anderson, K. A. Ockunzzi, and G. L. North, "Two-Dimensional Imaging of $\mathrm{OH}$ in a Lean Burning High Pressure Combustor," NASA TM 106854, (1995).

24. L. Melton and J. Verdieck, "Vapor/Liquid Visualization in Fuel Sprays," Twentieth Symposium (International) on Combustion, The Combustion Institute, Pittsburgh, 1283, (1984).

25. S. K. Aggarwal, G. Chen, T. A. Jackson, and G. L. Switzer, "Vaporization Behavior of Fuel Droplets in a Hot Air Stream," Int., J. Heat Mass Transfer, 34, No. 10, 2669, (1991).

26. M. M. Zaller and M. D. Klein, "Shear Coaxial Injector Cryogenic Spray Characterization," Advanced Earth-to-Orbit Propulsion Technology 1994, R. J. Richmond and S. T. Wu, eds., NASA CP-882, 2, 194, (1994).

27. N. M. Laurendeau, "Background Corrections for Laser-Induced Fluorescence Measurements of Nitric Oxide in Lean High-Pressure, Premixed Methane Air Flames," App. Opt., 36, No. 15, 3244, (1997). 
Public reporting burden for this collection of information is estimated to average 1 hour per response, including the time for reviewing instructions, searching existing data sources, gathering and maintaining the data needed, and completing and reviewing the collection of information. Send comments regarding this burden estimate or any other aspect of this collection of information, including suggestions for reducing this burden, to Washington Headquarters Services, Directorate for Information Operations and Reports, 1215 Jefferson Davis Highway, Suite 1204, Arlington, VA 22202-4302, and to the Office of Management and Budget, Paperwork Reduction Project (0704-0188), Washington, DC 20503.

\begin{tabular}{|l|l|l|}
\hline 1. AGENCY USE ONLY (Leave blank) & $\begin{array}{c}\text { 2. REPORT DATE } \\
\text { Month } 1998\end{array}$ & $\begin{array}{r}\text { 3. REPORT TYPE AND DATES COVERED } \\
\text { Technical Memorandum }\end{array}$ \\
\hline
\end{tabular}

\section{TITLE AND SUBTITLE} 5. FUNDING NUMBERS

Challenges to Laser-Based Imaging Techniques in Gas Turbine Combustor Systems for Aerospace Applications

6. AUTHOR(S)

Randy J. Locke, Robert C. Anderson, Michelle M. Zaller, and Yolanda R. Hicks

WU-537-05-20-00

\section{PERFORMING ORGANIZATION NAME(S) AND ADDRESS(ES)}

National Aeronautics and Space Administration

Lewis Research Center

Cleveland, Ohio 44135-3191

8. PERFORMING ORGANIZATION REPORT NUMBER

E-11368

\section{SPONSORING/MONITORING AGENCY NAME(S) AND ADDRESS(ES)}

National Aeronautics and Space Administration

Washington, DC 20546-0001

10. SPONSORING/MONITORING AGENCY REPORT NUMBER

NASA TM-1998-208649

AIAA-98-2778

\section{SUPPLEMENTARY NOTES}

Prepared for the 20th Advanced Measurement and Ground Testing Technology Conference sponsored by the American Institute of Aeronautics and Astronautics, Albuquerque, New Mexico, June 15-18, 1998. Randy J. Locke, Dynacs Engineering Company, Inc., 2001 Aerospace Parkway, Brook Park, Ohio 44142; Robert C. Anderson, Michelle M. Zaller, and Yolanda R. Hicks, NASA Lewis Research Center. Responsible person, Randy J. Locke, organization code 5520, (216) 433-6110.

Unclassified - Unlimited

Subject Category: 07

Distribution: Nonstandard

This publication is available from the NASA Center for AeroSpace Information, (301) 621-0390.

\section{ABSTRACT (Maximum 200 words)}

Increasingly severe constraints on emissions, noise and fuel efficiency must be met by the next generation of commercial aircraft powerplants. At NASA Lewis Research Center (LeRC) a cooperative research effort with industry is underway to design and test combustors that will meet these requirements. To accomplish these tasks, it is necessary to gain both a detailed understanding of the combustion processes and a precise knowledge of combustor and combustor subcomponent performance at close to actual conditions. To that end, researchers at LeRC are engaged in a comprehensive diagnostic investigation of high pressure reacting flowfields that duplicate conditions expected within the actual engine combustors. Unique, optically accessible flametubes and sector rig combustors, designed especially for these tests, afford the opportunity to probe these flowfields with the most advanced, laser-based optical diagnostic techniques. However, these same techniques, tested and proven on comparatively simple bench-top gaseous flame burners, encounter numerous restrictions and challenges when applied in these facilities. These include high pressures and temperatures, large flow rates, liquid fuels, remote testing, and carbon or other material deposits on combustor windows. Results are shown that document the success and versatility of these nonintrusive optical diagnostics despite the challenges to their implementation in realistic systems.

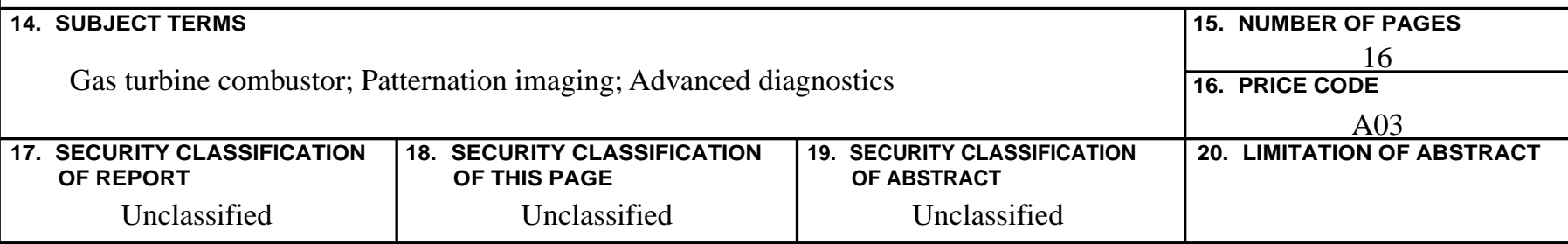

